\title{
Potential for top-down control on tropical tunas based on size structure of predator-prey interactions
}

\author{
Mary E. Hunsicker ${ }^{1,4, *}$, Robert J. Olson ${ }^{2}$, Timothy E. Essington ${ }^{1}$, Mark N. Maunder ${ }^{2}$, \\ Leanne M. Duffy ${ }^{2}$, James F. Kitchell ${ }^{3}$ \\ ${ }^{1}$ School of Aquatic and Fishery Sciences, University of Washington, Seattle, Washington 98195-5000, USA \\ ${ }^{2}$ Inter-American Tropical Tuna Commission, La Jolla, California 92037-1508, USA \\ ${ }^{3}$ Center for Limnology, University of Wisconsin, Madison, Wisconsin 53706, USA \\ ${ }^{4}$ Present address: College of Earth, Oceanic and Atmospheric Sciences, Oregon State University, Corvallis, Oregon 97331, USA
}

\begin{abstract}
The ecological consequences of widespread fisheries-induced reductions of large pelagic predators are not fully understood. Tropical tunas are considered a main component of apex predator guilds that include sharks and billfishes, and thus may seem unsusceptible to secondary effects of fishing top predators. However, intra-guild predation can occur because of size-structured interactions. We compiled existing data of apex predator diets to evaluate whether skipjack tuna Katsuwonus pelamis and yellowfin tuna Thunnus albacares might be vulnerable to top-down control by large pelagic predators in the eastern tropical Pacific Ocean. We identified potentially important predators of tunas by the frequency, quantity, and size and age of tunas in their diets and considered the degree that predated tunas could have potentially contributed to the reproductive output of the population. Our results indicate that the proportion of predator diets consisting of skipjack and yellowfin tunas was high for sharks and billfishes. These predators also consumed a wide size range of tunas, including subadults of the size capable of making a notable contribution to the reproductive output of tuna populations. Our study suggests that in the eastern tropical Pacific Ocean tropical tunas act as mesopredators more so than apex predators. Sharks and billfishes have the potential to play an important role in regulating these tuna populations. This study sets the stage for future efforts that could ascertain whether diminished levels of large predators have enhanced the production of tuna stocks and whether the trophic interactions of skipjack and yellowfin tunas should be explicitly accounted for when their population dynamics are assessed.
\end{abstract}

KEY WORDS: Predator release $\cdot$ Top-down control $\cdot$ Apex predators $\cdot$ Size structure $\cdot$ Ecosystembased management $\cdot$ Mesopredator $\cdot$ Reproductive value

Resale or republication not permitted without written consent of the publisher

\section{INTRODUCTION}

There is growing evidence in a diversity of marine ecosystems that apex predators can regulate the productivity and abundances of their prey populations (see Baum \& Worm 2009, Ritchie \& Johnson 2009). There is also widespread recognition that fishing has altered the structure of marine food webs through the selective removal of large-bodied predators (Estes et al. 1998, Jackson et al. 2001, Worm \& Myers 2003, Daan et al. 2005, Frank et al. 2005, Ward \& Myers 2005, Daskalov et al. 2007). Fishing can therefore be viewed as an important structuring agent in marine food webs, promoting productivity of meso- 
predators (i.e. species that occupy trophic positions immediately below apex predators) that thrive following the depletion of their larger-bodied predators (e.g. Worm \& Myers 2003, Frank et al. 2005, Polovina et al. 2009). A better understanding of the effects of predator removals on species dynamics is key to implementing ecosystem-based fisheries management. Identifying the magnitude and extent of these effects in many marine ecosystems remains a challenge owing to a paucity of historical data and monitoring surveys, and the confounding effects of dynamic ocean conditions (Essington 2010).

Top predators in high seas pelagic food webs have been subjected to large-scale fisheries for the past half-century. In the tropical Pacific Ocean, the apex predator guild (i.e. predators that occupy the top trophic positions and consume similar prey resources) is composed of large tunas, sharks and billfishes (Seki \& Polovina 2001, Kitchell et al. 2002). Highly valued skipjack tuna Katsuwonus pelamis and yellowfin tuna Thunnus albacares populations are the primary targets of purse seine and longline (yellowfin tuna only) fisheries. These populations are currently considered to be healthy and productive, and are above (skipjack tuna: Maunder \& Harley 2005) or near (yellowfin tuna:, Maunder \& Aires-daSilva 2009) management targets that maximize fishery catch. However, shark and some billfish populations have declined substantially over the last several decades as a result of fisheries exploitation and incidental catches (Baum et al. 2003, Ward \& Myers 2005, Sibert et al. 2006, Minami et al. 2007). The ecological consequences of reduced abundances of these large predators in the Pacific Ocean are becoming increasingly apparent. Recent studies indicate a shift in the north Pacific subtropical gyre food web, whereby smaller, fast-growing, short-lived mesopredators at mid-trophic levels have become more abundant in response to apex predator reductions (Ward \& Myers 2005, Polovina et al. 2009).

Tropical tunas, particularly yellowfin tuna, are often considered members of the apex predator guild and thus seem unlikely to be strongly regulated by predation. However, tunas are vulnerable to cannibalism and intra-guild predation from species that are also affected by commercial fishing activities. For example, large-bodied marlins commonly consume skipjack and yellowfin tunas (Brock 1984), pelagic sharks are widely viewed as opportunistic top predators (Cortes 1999), and skipjack and yellowfin tunas consume juvenile conspecifics with some regularity (King \& Ikehara 1956, Alverson 1963). Thus, it is possible that tropical tunas actually fill the role of meso- predators during much of their life history. If this hypothesis is true, their productivity may be enhanced by the depletion of larger-bodied species. This is a potentially important consideration for highseas fisheries management. Strategies to restore depleted shark and billfish populations (Gallucci et al. 2006, Kerstetter \& Graves 2006, Kaplan et al. 2007, Pine et al. 2008, Watson et al. 2009) could diminish the production capacity of tuna species (Kitchell et al. 1999, Cox et al. 2002, Olson \& Watters 2003) and thereby introduce conflicts and trade-off issues between the economic objectives of tuna fisheries and the conservation and economic objectives for billfishes and sharks.

Here, we evaluate whether large-bodied apex predators might be capable of regulating skipjack and yellowfin tuna populations. Strong top-down interactions can be identified by population modeling and statistical analysis of retrospective data (Worm \& Myers 2003, Frank et al. 2005) or by bioenergetics principles (Williams et al. 2004). However, the information needed to support these approaches is not available for most pelagic fishes inhabiting open-ocean ecosystems. Instead, we adopt an approach used to gauge the importance of anthropogenic-induced mortality on large pelagic species: one that considers the life history stages affected and the reproductive potential of the fish at those stages (Maunder \& Harley 2005, Gallucci et al. 2006, Wallace et al. 2008, 2010). Estimates of reproductive potential have been used to identify the ages and sizes of fish in the population that are most valuable for future population growth, and therefore should be avoided by fisheries. (Caddy \& Seijo 2002, Maunder \& Harley 2005). We use similar criteria to distinguish between ontogenetic changes in predation risk of a species versus its overall vulnerability to predators, revealing the predators that are most likely to regulate tuna productivity. We presume that predators that consume substantial numbers of the large juvenile or sub-adult tunas that have notable reproductive potential can have a potentially important impact on the intrinsic rates of growth, biomass and, ultimately, sustainable catch levels of tuna populations. Thus, predators that prey on tunas that have high reproductive value are the species most likely to regulate tuna productivity.

This study provides the most detailed and comprehensive evaluation of intra-guild predation on tropical tunas to date. Unique to this work is the development and use of an apex predator food habits database that includes summarized data on nearly 25 predator groups and primary data on 65 predator 
groups inhabiting the Pacific Ocean. We compiled all known apex predator food habits data from published papers and reports, and digitized primary data records from sampling ventures that span more than 5 decades. The spatial extent of the summarized data includes much of the range of the tropical tunas in the Pacific Ocean, while the primary data are restricted to a large portion of the eastern tropical Pacific Ocean. To the primary data we applied statistical models to develop robust estimates of predation frequency and intensity and also to explore important environmental and biological covariates. We then examined the size structure of tropical tunas consumed by top predators to estimate reproductive potential at size to infer the amount of reproductive potential that is lost to predation.

\section{MATERIALS AND METHODS}

\section{Food habits data}

On the basis of 3 methods, we compiled data on the food habits of large- and medium-bodied fishes commonly considered to be apex predators. First, we compiled primary data from 3 food habit studies of the Inter-American Tropical Tuna Commission (IATTC) into a common database format. Second, we

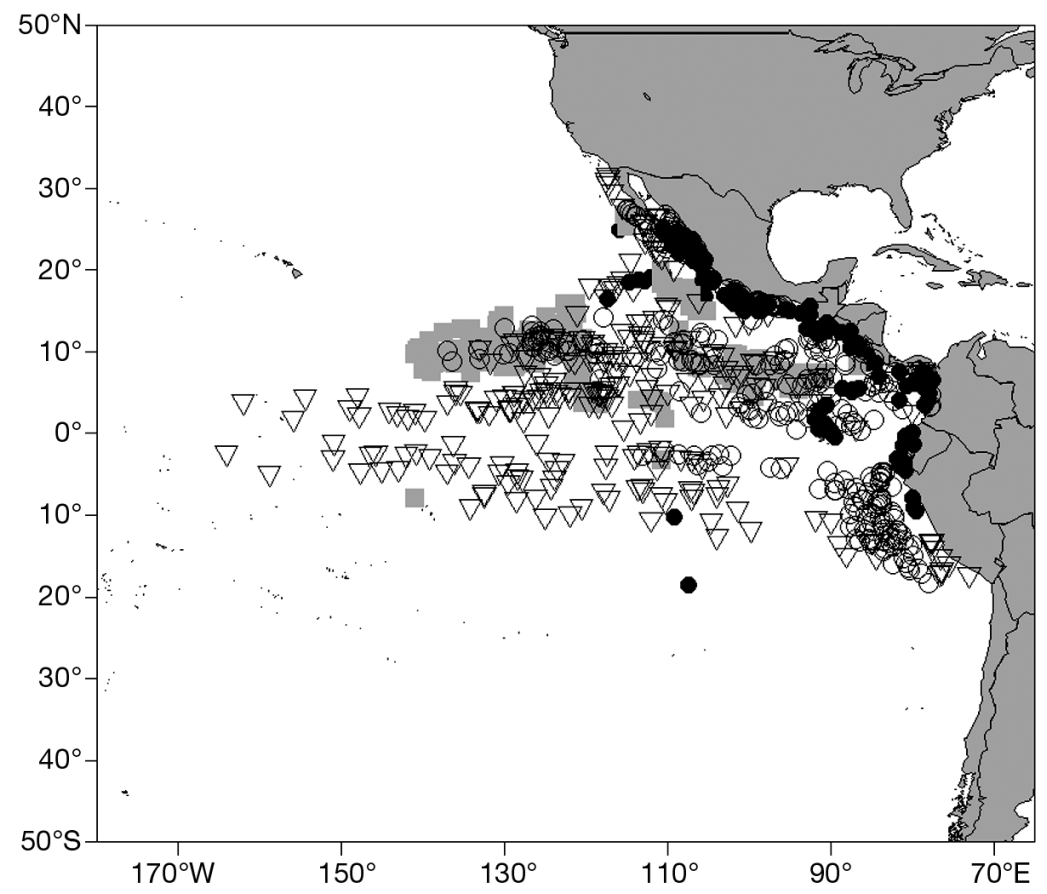

Fig. 1. Sampling locations of predators for which primary data were available. Black circles: Years 1955 to 1960; gray squares: Years 1969 to 1972; open circles: Years 1992 to 1994; open triangles: Years 2003 to 2005 digitized primary data reported in archived data sheets belonging to the IATTC (see Supplement at www.int-res.com/articles/suppl/m445p263_supp.pdf for details). Third, we compiled published food habits data summarized in either reports or peer-reviewed publications (see Supplement). The resulting dataset is a compilation of both primary and summarized data that lend themselves to different types of analyses. The primary data contained detailed information on individual samples and were used for formal statistical analyses. The summarized data provided accounts of the feeding habits of various predators, which we used to generate broad comparisons across predator taxa and assess the generality of the findings across regions of the tropical Pacific Ocean.

The primary data came from an area that encompassed waters south of the Hawaiian Islands and a large portion of the eastern Pacific Ocean (Fig. 1). These data were clustered among 2 historical periods (1955 to 1960, 1969 to 1972) and 2 contemporary periods (1992 to 1994, 2003 to 2005). Primary data from the contemporary period were collected by observers aboard purse-seine fishing vessels and consisted of approximately 65 predators, whereas data from the historical period contained information on the feeding habits of only yellowfin tuna. The primary contemporary data provided information on individual predators, including prey composition, date and time of capture, capture method and gear, the precise spatial coordinates and sea surface temperature (SST) at the capture locations, as well as predator and prey sizes. The historical data were for yellowfin tuna sampled at canneries and therefore did not contain the same degree of detail regarding sampling dates, locations, and SSTs.

In total, the summarized data included nearly 24 predator taxa from 37 published reports or journal articles. At a minimum, these data sources contained information on the range of predator body sizes sampled and the proportional contribution of prey species to predator diets. The spatial extent of the summarized data spanned much of the geographical range of skipjack and yellowfin tunas in the Pacific Ocean and the temporal coverage ranged from the mid-twentieth century to the present. We noted that less than half of the sharks and billfishes sampled for diet composition were large adults, and samples also included small individuals. For 
example, $18 \%$ of the shark specimens were smaller than $90 \mathrm{~cm}$ total length, and $62 \%$ were smaller than $150 \mathrm{~cm}$ (range, 39 to $315 \mathrm{~cm}$ ). This is consistent with the shark bycatch composition for the same years (Román-Verdesoto \& Orozco-Zöller 2005).

\section{Contribution of tunas to predator diets}

We fitted generalized linear mixed models (GLMMs) to the primary food habits data to identify the predators that consume tunas more frequently and in relatively higher quantities, while accounting for confounding physical and biological factors and potential sampling biases. Pseudo-replication is a concern when the stomachs of several predators are collected at the same sampling event (e.g. from the same purse-seine set). Because these stomach samples are not independent, we modeled the relationship between individual samples and sampling events as random effects (sampling event as grouping variable, Gelman \& Hill 2007).

Our analysis of primary data also needed to account for sampling biases associated with changes in the methods of catching tunas and other predators over time (via fishing vessels) ${ }^{1}$. The widespread use of human-made floating-objects, i.e. fish aggregating devices (FADs), in tuna purse-seine fisheries began after the 1969 to 1972 sampling period. Most purseseine sets on FADs are made in the early morning when the stomachs of most predators tend to be empty, and predators with empty stomachs were excluded from the analysis to account for this sampling bias. Recently consumed tunas were also excluded from the analysis to omit predation that probably occurred while the fish were encircled in the purse seines. Lastly, for cases in which primary data contained prey items that could be only identified to the genus Thunnus, we assumed that these prey were yellowfin tuna. This assumption was based on the observation that yellowfin tuna was the most common species of Thunnus preyed upon, based on archived predator food habits records for prey that were possible to identify ( 95\% of Thunnus species consumed by predators were yellowfin tuna).

\footnotetext{
1Purse-seine sets are made in 3 different ways in the eastern tropical Pacific Ocean. In 'dolphin sets' the net is deployed around the tuna-dolphin aggregation after a chase by speedboats; in 'floating-object' sets, the net is deployed around or next to flotsam or fish-aggregating devices that attract tunas; in 'unassociated sets', the net is deployed around free-swimming schools.
}

Because of the high number of zeros in the data (i.e. many stomachs that contained no tunas), standard statistical probability distributions could not be used. Instead we used a mixture model (also known as delta-normal or 2-stage hurdle model; e.g. Maunder \& Punt 2004, Jensen et al. 2005, Reum et al. 2011) wherein 2 separate models, describing the frequency of occurrence and the mean mass (\%) conditional on a tuna being present, were fit separately. The 2 stages were then combined by taking the product of the predicted values to generate an overall predicted diet proportion.

In the first stage, we modeled the presence/ absence data for skipjack and yellowfin tunas by using a binomial probability density function and logit link function

$$
\operatorname{logit}(y)=\log [y /(1-y)]=\beta x_{i t}+\alpha_{i}+\varepsilon_{i t}
$$

where $y$ is the probability that a tuna was present in the stomach of predator $i$ at time $t, x_{i t}$ is a vector of fixed effects, $\beta$ is a vector of coefficients, $\alpha_{i}$ is a random effect (i.e. fishing set identification [ID]) and $\varepsilon_{i t}$ is the error term. The random effect is assumed to be distributed as $\mathrm{N}\left(0, \sigma_{\alpha}^{2}\right)$

Second, for those stomach samples in which tunas were found, we estimated the proportional mass contribution of skipjack and yellowfin tunas to the total food mass in the stomach of each individual predator. Hence, we refer to the response variable as the conditional percent mass contribution $(u)$. For this second-stage analysis, we normalized the proportion estimates with the arcsine-square root transformation (Zar 1999) and modeled the response variable as a Gaussian (normal) probability density function with the identity link function

$$
u=\beta x_{i t}+\alpha_{i}+\varepsilon_{i t}
$$

This model is equivalent to a multiple regression model with a random effects term. In addition, we weighted the likelihood of each data point so that diet proportions of actively feeding fish were given more weight than the diet proportions of fish with few prey in their stomachs. The weighting term is the ratio of predator stomach mass to fish mass.

To account for the confounding effects of spatial and temporal factors on predators' feeding habits, we formulated a suite of candidate models that included all combinations of 1,2 or 3 sets of fixed effects (Table 1). The sets of potential model covariates were the following: time period (datasets 1955 to 1960, 1969 to 1972,1992 to 1994,2003 to 2005), season/ quarter (winter, December to February; spring, March to May; summer, June to August; autumn, 
Table 1. Candidate models used to identify the frequency of occurrence and conditional percent mass contribution of skipjack tuna (SKJ) and yellowfin tuna (YFT) in the diets of apex predators in the eastern tropical Pacific Ocean based on primary food habits data. Fixed effects, number of parameters $(\mathrm{K})$ and $\triangle \mathrm{AIC}$ values (AIC values - minimum AIC value) for the generalized linear mixed models are shown. Numbers of estimated parameters (K) in YFT models are denoted in parentheses. Each model included an intercept and random effect term (fishing set). See 'Contribution of tunas to predator diets' for model descriptions. Lat: latitude; Lon: longitude

\begin{tabular}{|c|c|c|c|c|c|c|c|}
\hline \multirow[b]{2}{*}{ ID } & \multirow[b]{2}{*}{ Candidate models } & \multicolumn{3}{|c|}{ Frequency of occurrence } & \multicolumn{3}{|c|}{ Composition by mass } \\
\hline & & $\mathrm{K}$ & $\Delta \mathrm{AIC}_{\mathrm{SKJ}}$ & $\Delta \mathrm{AIC}_{\mathrm{YFT}}$ & $\mathrm{K}$ & $\Delta \mathrm{AIC}_{\mathrm{SKJ}}$ & $\Delta \mathrm{AIC}_{\mathrm{YFT}}$ \\
\hline 1 & Predator & $13(11)$ & 11 & 0.07 & $14(12)$ & 28 & 16 \\
\hline 2 & Lat + Lon + Area & 7 & 115 & 198 & 8 & 7 & 19 \\
\hline 3 & Dataset + Season & 8 & 122 & 202 & $8(9)$ & 14 & 29 \\
\hline 4 & Set/Gear & 5 & 85 & 175 & $5(6)$ & 0 & $\mathbf{0}$ \\
\hline 5 & Predator + Lat + Lon + Area & 18(16) & 3 & 4 & 19 (17) & 30 & 33 \\
\hline 6 & Predator + Set/Gear & $16(14)$ & 0 & 0 & $16(15)$ & 22 & 22 \\
\hline 7 & Predator + Dataset + Season & $19(17)$ & 9 & 5 & 19 (18) & 35 & 28 \\
\hline 8 & Lat + Lon + Area + Set/Gear & 10 & 85 & 178 & $10(11)$ & 7 & 18 \\
\hline 9 & Lat + Lon + Area + Dataset + Season & 13 & 106 & 193 & $13(14)$ & 18 & 43 \\
\hline 10 & Set/Gear + Dataset + Season & 11 & 88 & 177 & $10(12)$ & 14 & 23 \\
\hline 11 & Predator + Lat + Lon + Area + Set/Gear & $21(19)$ & 1 & 5 & $21(20)$ & 29 & 40 \\
\hline 12 & Predator + Lat + Lon + Area + Dataset + Season & $24(22)$ & 7 & 6 & $24(23)$ & 40 & 44 \\
\hline 13 & Predator + Set/Gear + Dataset + Season & $22(20)$ & 7 & 1 & $21(21)$ & 35 & 35 \\
\hline 14 & DataSet + Season + Lat + Lon + Area + Set/Gear & 16 & 89 & 175 & $15(17)$ & 20 & 39 \\
\hline 15 & Predator + Lat + Lon + Area + Set/Gear + Dataset + Season & $27(25)$ & 7 & 3 & 26 & 41 & 50 \\
\hline
\end{tabular}

September to November), set type/gear (purse-seine floating-object sets, dolphin sets and unassociated sets, and pole-and-line gear), space (latitude, longitude, area [Areas 1 to 4]) and predator (see Table 2 for levels). Latitude and longitude were continuous variables, and before the analysis they were standardized to have mean values of 0 and variances of 1 to simplify interpretation of the coefficients. The remaining fixed effects were categorical.

Our modeling of primary food habits data took into account inconsistencies in the historical food habits records. During the 1969 to 1972 sampling period, predators were sampled from wells (i.e. partitions in the hold of the vessel into which the catch is delivered) that contained multiple sets (typically 3 to 5 sets), each with known dates and locations and each in proximity to one another (i.e. within $<1^{\circ}$ by latitude and longitude). Given that the exact set that yielded a sample could not be determined, we averaged the estimates of latitude and longitude at the possible locations from which an individual was captured to generate a single value of these physical parameters for each predator. To further account for the confounding effects of space we included spatial area as a model covariate. Four distinct areas (quadrants) were determined from the median latitudinal and longitudinal coordinates of a predator-sampling location. We could not include SST as an environmental variable; SST was routinely collected in the contemporary sampling period, but not during the historical period, and we were unable to reconstruct SST at many of the 1950s sampling locations. The data for predator taxon/taxa that consumed tunas but for which there were low sample sizes $(\mathrm{n}<20)$, were combined into higher taxonomic groupings. One consequence of this modification is that the number of predators considered in the GLMMs (and, hence, the number of estimated parameters) differed between the skipjack and yellowfin tuna models (Tables 1 \& 2). Predator taxon/taxa were excluded from the analysis if relevant prey species (i.e. skipjack or yellowfin tuna) were absent in all stomach samples.

We tested the candidate models separately for the 2 stages of the mixture model (Eqs. 1 \& 2). In general, the set of candidate models were the same between the binomial component (Eq. 1) and the Gaussian component (Eq. 2). There were a few exceptions because of limited data for the Gaussian part of the model. The dataset '1955-1960' (see Supplement) and the gear type 'pole and line' were not included as variables in the models for skipjack tuna owing to low sample numbers. The GLMMs were fitted using the glmer function in the lme4 package in $\mathrm{R}(\mathrm{R}$ Development Core Team 2010) and model selection was based on Akaike's information criterion (AIC; Akaike 1973, Burnham \& Anderson 2002). For each modeling framework, we deemed candidate models with a $\triangle$ AIC value of less than 3 (i.e. within 3 units of the lowest AIC model) to have substantial support based on the data.

Finally, we generated standardized diet fractions for each predator. These estimates describe the proportional contribution by mass that skipjack and yel- 


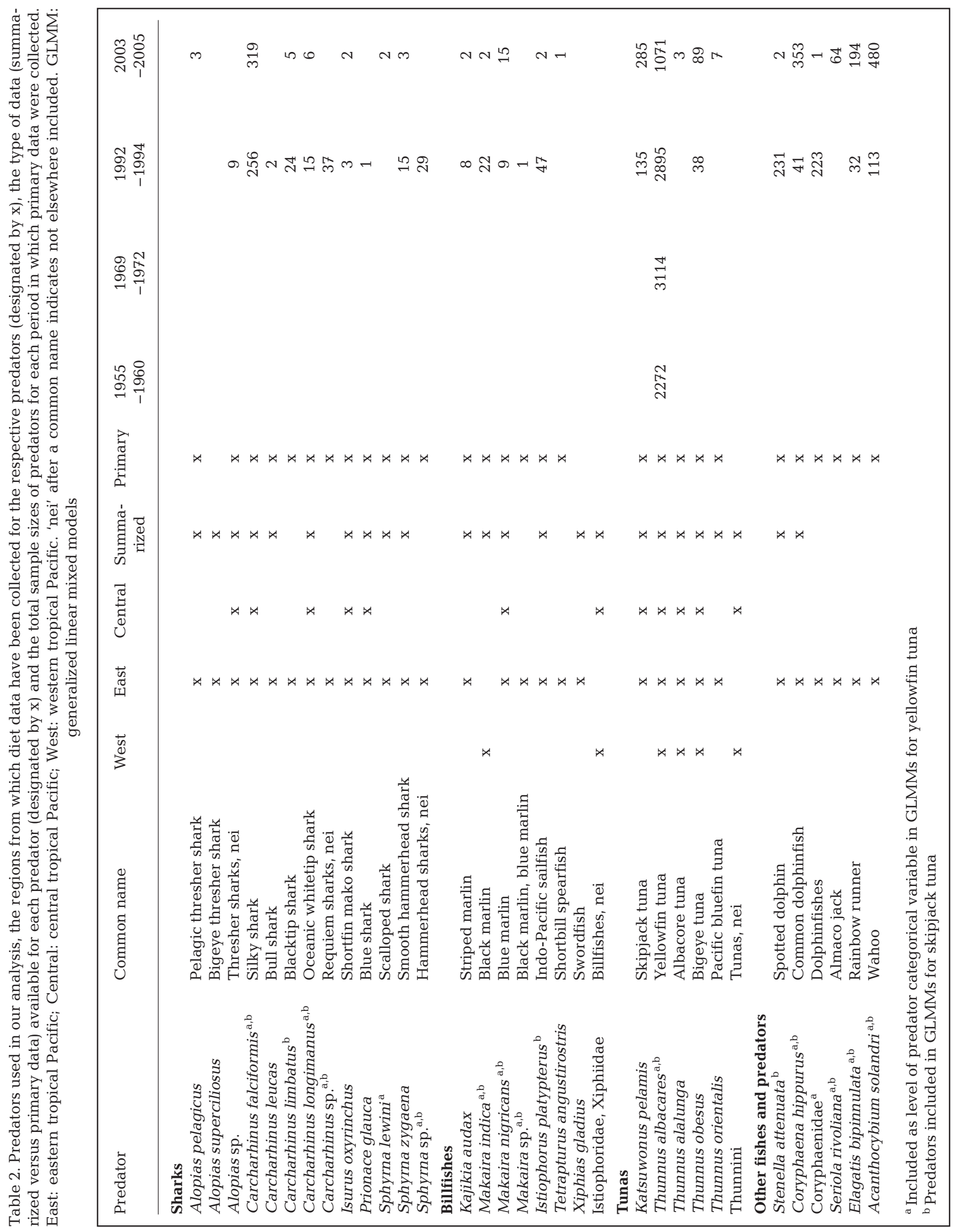


lowfin tunas comprise for each predator taxon or taxa and were standardized for location, set type and other potential covariates. First, we predicted the occurrence $(\hat{y})$ and conditional proportion by mass ( $\hat{u})$ of tunas in predator diets based on the best-fitting models. We then multiplied the predicted values from the 2 stages to determine the expected proportion by mass of skipjack and yellowfin tunas in predator diets $(\hat{\mathrm{C}})$, i.e.

$$
\hat{\mathrm{C}}=\hat{\mathrm{Y}} \times \hat{\mathrm{u}}
$$

\section{Broad comparisons of predator diets}

We made broad comparisons of predation on skipjack and yellowfin tunas across predator taxon or taxa for the entire tropical Pacific Ocean to evaluate the generality of the results gleaned from the analysis of primary data from the eastern tropical Pacific Ocean. Using the summarized published diet data, we calculated the mean frequency of occurrence and proportional contribution by mass of tunas to the diets of sharks, billfishes, yellowfin tuna, skipjack tuna and other tuna species (Table 2, see also 'Description' and Table S1 in the supplement). Other tunas included albacore tuna Thunnus alalunga, bigeye tuna T. obesus and Pacific bluefin tuna T. orientalis. All predator taxa included in this analysis are listed in Table 2. We also made regional comparisons of predation by comparing the mean frequency of occurrence of skipjack and yellowfin tunas in the stomach contents; summarized food habits data were not available for sharks and skipjack in all 3 regions of the tropical Pacific Ocean (i.e. eastern, central and western, Table 2).

\section{Prey sizes and reproductive potential}

We identified the sizes at which skipjack and yellowfin tunas were vulnerable to predation by apex predators in the eastern tropical Pacific Ocean from the primary food habits data. Estimates of individual prey body sizes consumed by individual predators were recorded during the contemporary sampling periods only (1992 to 1994 and 2003 to 2005). Fork lengths were measured for 45 skipjack tuna and 66 yellowfin tuna. We calculated the mean and 95\% CI values of the sizes of skipjack and yellowfin tunas consumed by sharks, billfishes and large-bodied tunas.

We estimated the relative reproductive potential of the skipjack and yellowfin tunas that are at the age and size most commonly consumed by apex predators. Reproductive potential is defined as the expected number of eggs that an individual of a particular age would produce over its remaining lifetime, given that it has already survived to that age (Gotelli 2001). This value is a function of the fecundity and survivorship of a fish at the different stages of its remaining life, and we present estimates for each length class relative to the maximum estimate of reproductive potential.

The reproductive potential $(v)$ was calculated for all age/size classes $z$ (Gotelli 2001) as

$$
v(z)=\frac{\sum_{y=z+1}^{k} l(y) b(y)}{l(z)}
$$

where $b(y)$ is the fecundity of an individual at age $z$ or older, and $l(y)$ is annual survivorship for an individual at age $z$ or older and $l(z)$ is annual survivorship for an individual at age $z$. Essentially, we generated estimates of reproductive potential under unexploited conditions by taking virgin recruitment and using the natural mortality rate to calculate numbers at age. The numbers at age were then multiplied by fecundity at age and summed to get total reproductive potential of an unexploited stock. Here, $b(y)$ was calculated by using age-specific estimates of fecundity, proportion of females (sex ratio) and the percentage of females that are mature (see Table S2). Estimates of $l(z)$ were calculated from estimated agespecific natural mortality rates for combined male and female skipjack tuna (Maunder \& Harley 2005) and yellowfin tuna (Maunder \& Aires-da-Silva 2009; see Table S2). These estimates are taken from the official stock assessments for these species and are supported by tagging data (Hampton 2000). We recognize that fishing is a large source of mortality on skipjack and yellowfin tunas, and that relative reproductive potential of smaller tunas will be different under exploitation. For instance, if the fishery targets tunas that are larger than those consumed by predators, we may expect that the relative reproductive potential of the tunas being predated on will increase compared with those of larger-sized tunas. However, fishing is highly variable in intensity and selectivity and the reproductive potential of individual tunas is sensitive to estimates of mortality at age. Thus, to generate more stable estimates of tuna reproductive potential we modeled reproductive value under unexploited conditions. The parameter values used in our analysis were obtained from previously published literature and stock assessment 
reports (Schaefer 1998, Maunder \& Harley 2005, Maunder 2007, Maunder \& Aires-da-Silva 2009). Sex-specific information and estimates of fecundity were not available for Pacific skipjack tuna, so fecundity at age was assumed to be proportional to weight at age. This is a standard assumption in fisheries stock assessment and is used in a majority of assessments. We converted the estimates of reproductive potential at each age class to estimates at length by using published length-at-age relationships for skipjack (Bayliff 1988) and yellowfin (Wild 1986) tunas.

\section{RESULTS}

\section{Tunas in predator diets}

The frequency of occurrence of skipjack and yellowfin tunas in predator stomach samples were best predicted by models that included only predator taxon/taxa and set/gear type (Model 6 in Table 1). For skipjack tuna, the model with predator taxon/taxa, location of capture and fishing set/gear type as predictors also fit the data well (Model 11 in Table 1). For yellowfin tuna, the model with only predator taxon/ taxa as a predictor variable (Model 1) performed nearly as well as the best-fitting model (Model $\triangle \mathrm{AIC}=0.07$ ). The coefficients of the best-fitting models indicated that the frequency of predation on both species was greatest in floating-object sets, intermediate for dolphin sets and lowest in the unassociated school sets and pole-and-line fisheries (see Table S3 for detailed listing of model coefficients). 'Dataset' was not included in the best-fitting models for skipjack and yellowfin tunas, which suggests that the occurrence of these tunas in predator diets did not change over time or that a change could not be detected based on the available data.

We identified the predators that had the highest probability of consuming skipjack and yellowfin tunas based on model coefficients from these bestfitting models. We found that skipjack tuna were found most frequently in the diets of blacktip sharks Carcharhinus limbatus, silky sharks C. falciformis, Indo-Pacific sailfish Istiophorus platypterus and marlins Makaira spp. and were found least frequently in the diets of spotted dolphins Stenella attenuata, yellowfin tuna and dolphinfish Coryphaena hippurus. Of the large pelagic fishes and tunas, requiem sharks Carcharhinus spp., hammerhead sharks Spyrna spp. and marlin Makaira spp. were most likely to consume yellowfin tuna while large-bodied conspecifics were the least likely to consume them (see Table S3).
Several species were never found to have consumed skipjack or yellowfin tunas (primary data): bigeye tuna Thunnus obesus, black skipjack tuna Euthynnus lineatus, skipjack tuna and spinner dolphin Stenella longirostris.

The conditional percent mass contribution of skipjack and yellowfin tunas were best predicted by capture method alone. Generally, skipjack and yellowfin tunas comprised the greatest proportion in predator diets in unassociated and floating-object sets, compared with other fishing methods (see Table S3).

Standardized diet fractions (proportion of predator diet, by mass, consisting of skipjack and yellowfin tunas) were highest for sharks and marlins (Fig. 2). The expected proportion by mass of skipjack tuna in the diets of blacktip sharks diets was approximately $47 \%$. The expected proportions by mass of yellowfin tuna in the diets of sharks and marlins reached nearly 40 and $18 \%$, respectively (Fig. 2). Moreover, the standardized diet fractions indicated that skipjack and yellowfin tunas were a more important prey of predators captured in floating-object sets compared with the other fishing methods (estimates based on the center of the sampling distribution; Fig. 2). Standardized diet fractions by predator and set/gear type were estimated only when at least 3 predators of the same species were captured in a given set/gear type.

\section{Broad comparisons of predator diets}

The compilation of summarized diet data from locations throughout the tropical Pacific Ocean confirmed the importance of skipjack and yellowfin tunas in the diets of large-bodied predators found in the eastern Pacific Ocean (Fig. 3). The summarized data also revealed potential regional differences in predation on these tuna species (Fig. 4). Overall, the frequency of occurrence of skipjack tuna in predator diets was greatest for billfishes. Skipjack tuna also comprised a considerable portion of sharks' diets and the diets of large-bodied yellowfin tuna and conspecifics (Fig. 3). This finding differs from our analysis of the primary data for the eastern Pacific alone, which suggested that sharks consumed skipjack tuna more often than did billfishes and that there was little to no predation on skipjack by conspecifics or other tuna species. This discrepancy could be attributed to regional differences in predation. Our analysis of the summarized data revealed a higher occurrence of skipjack tuna in the diets of large-bodied yellowfin tuna and conspecifics in the western and central 

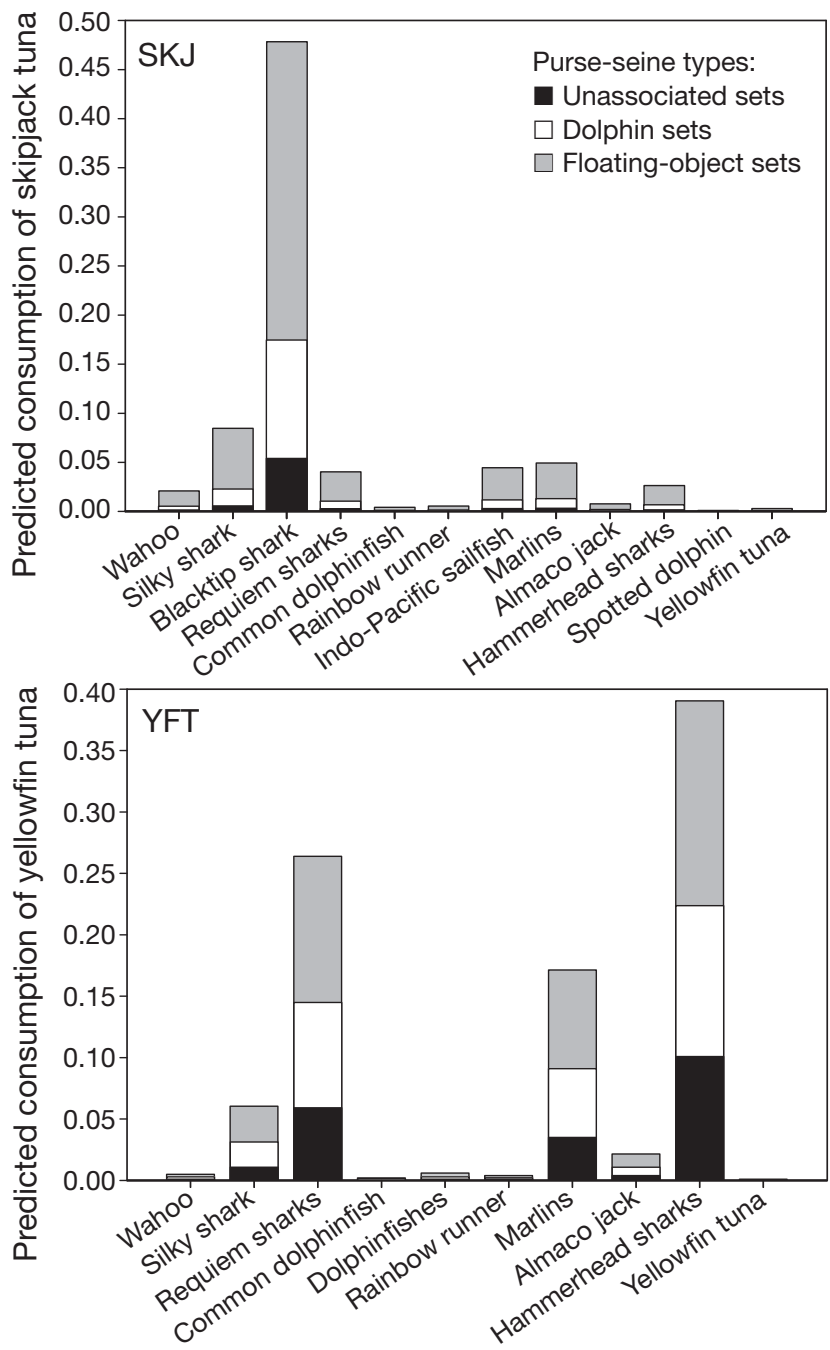

Fig. 2. Overlapping bar plot (all bars start at 0) of the predicted consumption of skipjack tuna (SKJ) and yellowfin tuna (YFT) as a function of predator and fishing method (set/gear type). Predictions were generated from mixture models (also known as delta-normal or 2 stage hurdle model) fit to the frequency of occurrence and conditional mass (\%) of tunas in predators' stomachs determined from primary food habits data. Predictions for pole-and-line fishing are not included because this fishing method was only used to capture yellowfin tuna during the historical period

regions of the Pacific Ocean compared with the eastern region (Fig. 4). This regional gradient of predation was also observed for sharks and was particularly notable for billfishes (Fig. 4). The occurrence of skipjack tuna in billfish diets was as much as 40 and $30 \%$ in the western and central Pacific Ocean, respectively, whereas the highest estimate of occurrence in the eastern region was approximately $3 \%$ (in blue marlin Makaira nigricans).

Over all the regions of the tropical Pacific Ocean, the frequency of occurrence of yellowfin tuna in predator diets was greatest for sharks and billfishes

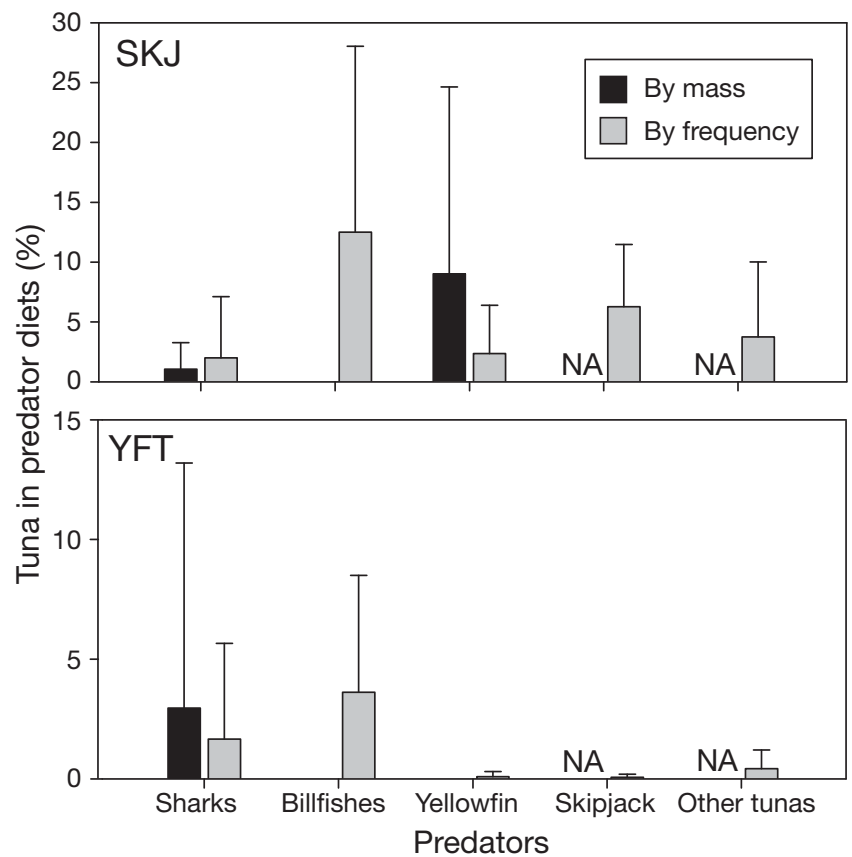

Fig. 3. Mean (+SD) contributions of skipjack tuna (SKJ) and yellowfin tuna (YFT) tunas in the diets of apex predators in the tropical Pacific Ocean. Estimates are based on summarized data sources. 'Other tunas' category includes albacore, bigeye and Pacific bluefin tunas. NA: data not available
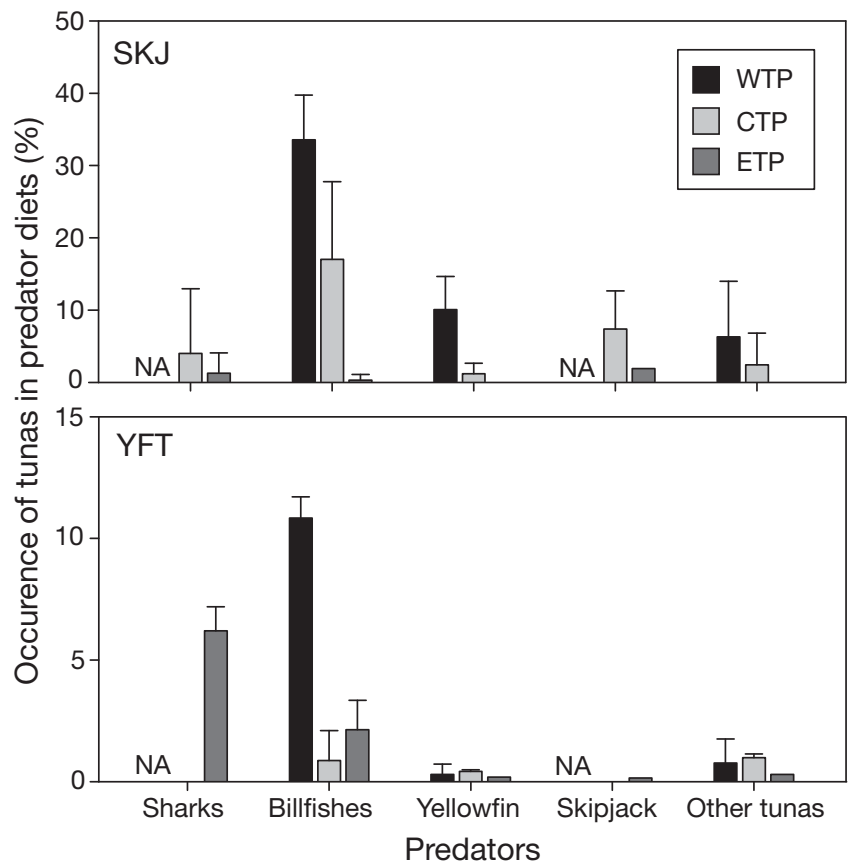

Fig. 4. Mean (+SD) percent frequency of occurrence of skipjack tuna (SKJ) and yellowfin tuna (YFT) in the diets of apex predators in the eastern (ETP), central (CTP) and western (WTP) tropical Pacific Ocean. Estimates are based on summarized data sources. 'Other tunas' category includes albacore, bigeye and Pacific bluefin tunas. NA: data not available 
and least for large-bodied conspecifics and other tuna species (Fig. 3). This finding is consistent with our analysis of primary data from the eastern tropical Pacific Ocean. The summarized diet data did not reveal a regional gradient of predation on yellowfin tuna by large-bodied predators; however, there are regional differences. Similar to our findings for skipjack tuna, the occurrence of predation on yellowfin tuna by billfishes was greatest in the western tropical Pacific Ocean compared with the central and eastern regions (Fig. 4).

\section{Prey sizes and reproductive potential}

Large-bodied predators consumed a wide size range of tunas, ranging from early life stages to subadults. Predators consumed skipjack tuna with body sizes up to $80 \mathrm{~cm}$ in length (Fig. 5). The mean lengths of skipjack tuna consumed by billfishes, sharks and tunas were 26, 27 and $19 \mathrm{~cm}$, respectively. The maximum size of yellowfin tuna consumed by predatory fishes was approximately $100 \mathrm{~cm}$ and the mean body sizes of yellowfin tuna consumed by billfishes, sharks and tunas were 45, 37 and $22 \mathrm{~cm}$, respectively (Fig. 5).

Because large predatory fishes preyed upon a wide size range for both skipjack and yellowfin tunas, the reproductive potential of individuals that were consumed also ranged widely (Fig 5). For both species we found predation on size classes that had notable reproductive potential (Fig. 5). Reproductive potential in skipjack tuna is maximized at approximately age $1.5 \mathrm{yr}$ (body length $\approx 60 \mathrm{~cm}$ ), while for yellowfin tuna it is greatest at age $3 \mathrm{yr}$ (body length $\approx 125 \mathrm{~cm}$ ). Approxi-
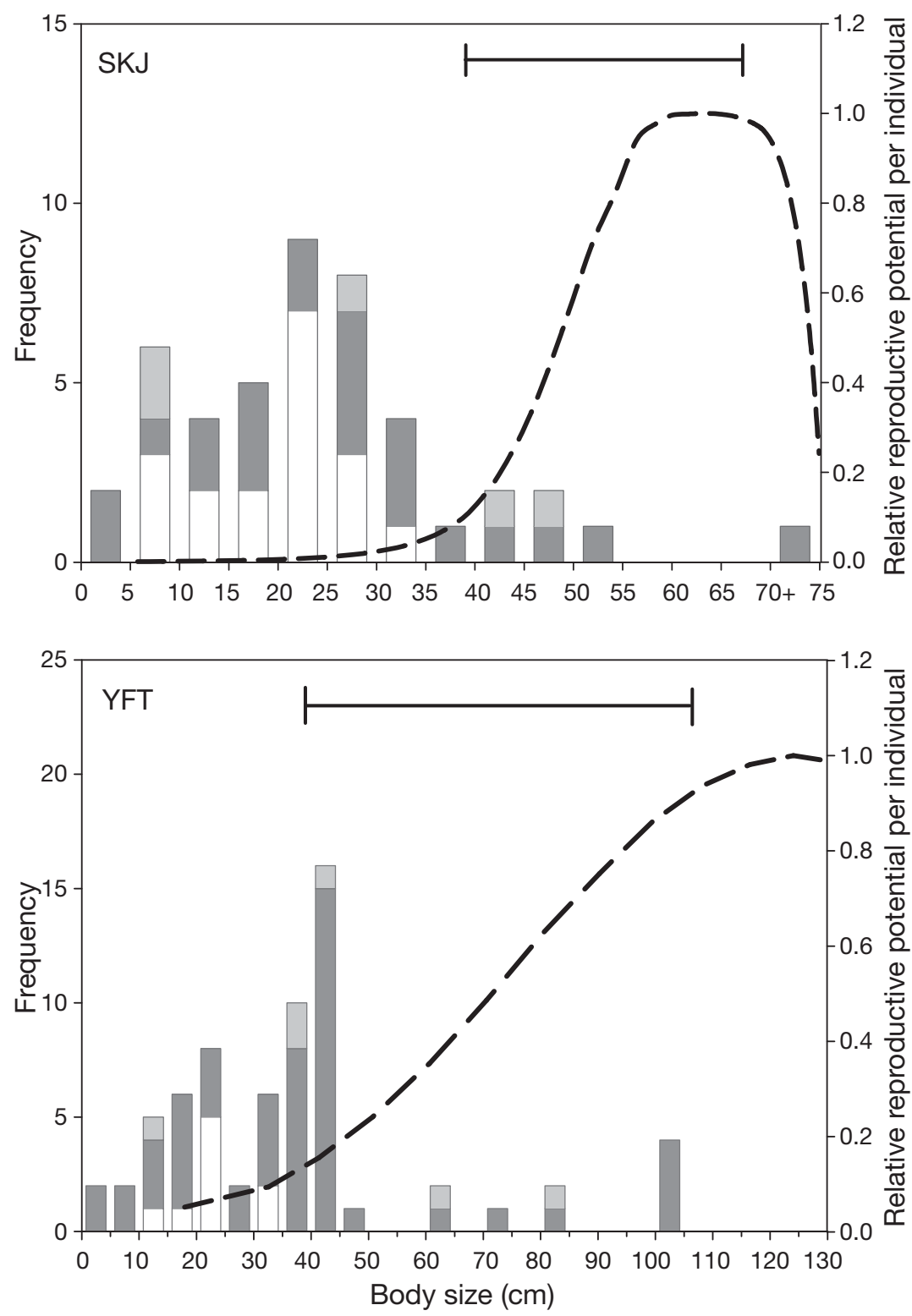

Fig. 5. Frequency (number) of skipjack tuna (SKJ) and yellowfin tuna (YFT), by body size, consumed by sharks (dark gray bars), marlins (light gray bars) and large-bodied tunas (white bars) in the eastern tropical Pacific Ocean. Dashed black lines represent estimates of the relative reproductive potential of individual skipjack and yellowfin tunas across size classes. Solid black lines denote the body sizes that comprise $90 \%$ of tuna catches mately $13 \%$ of all the skipjack tuna found in predator stomachs had a reproductive potential that exceeded $20 \%$ of the maximum. Similarly, $15 \%$ of all yellowfin tuna found as prey had a reproductive potential that exceeded $20 \%$ of the maximum. However, for some predator taxa, this was greater; sharks and billfishes consumed skipjack and yellowfin tunas with estimated ages that had reproductive potentials as great as $60 \%$ of the maximum (Fig. 5). Evidence of a single skipjack tuna $>70 \mathrm{~cm}$ in

length and 4 yellowfin tuna $>100 \mathrm{~cm}$ in length in the stomachs of sharks (Fig. 5) suggests that top predators are also capable of consuming larger tunas that have even higher reproductive value. The overall trend of relative reproductive potential was the same when we used estimates of fecundity for Indian Ocean skipjack tuna (from Stéquert \& Ramcharrun 1995) in our calculations. 


\section{DISCUSSION}

Tropical tunas, particularly yellowfin tuna, are often considered apex predators in pelagic food webs in the Pacific Ocean. However, our findings suggest that tropical tunas at large body sizes are consistently preyed upon by a guild of large-bodied predators and therefore are better considered as mesopredators. Both a detailed analysis of primary data collected in a single, large region and a synthesis of previously published diet studies conducted throughout the tropical Pacific Ocean support the hypothesis that these tropical tunas comprise a substantial component of the diet of sharks and billfishes. Although much of this predation was directed at very smallsized tunas - a pattern of ontogenetic predation risk not uncommon among marine fishes - we find that predation also extends to later life history stages, including those that have significant reproductive value. Thus, predation by sharks and billfishes has the potential to play an important role in regulating skipjack and yellowfin tuna populations. The question of top-down control on tropical tunas remains to be answered, but our work will provide future research efforts with essential knowledge about potentially important predators on tunas and their vulnerability to predation based on size.

The possibility that sharks and billfishes could regulate tropical tuna populations raises 2 questions. The first is whether current levels of skipjack and yellowfin tuna productivity may have been fostered by the reduction of large-bodied predators by industrial fishing (Ward \& Myers 2005). For example, if tropical tunas are indeed regulated in part by these predators, the high levels of skipjack tuna productivity observed over the past decade (e.g. Sibert et al. 2006) could represent a shifting baseline (Pauly 1995, Pinnegar \& Engelhard 2008). A second, related question is whether the potential recovery of sharks and billfishes might lead to secondary effects on skipjack and yellowfin tunas. Fishing can modify the structure and functioning of marine systems (see Baum \& Worm 2009), and increasing efforts are being made to foster a rebuilding of shark (Gallucci et al. 2006, Watson et al. 2009) and billfish (Kitchell et al. 2004, Kerstetter \& Graves 2006, Kaplan et al. 2007, Pine et al. 2008) populations. Recovery of depleted species can have surprising consequences when there are high interaction strengths between exploited species. For instance, the recovery of Barents Sea cod Gadus morhua coupled with fishing on their prey, capelin Mallotus villosus, contributed to a collapse in the capelin population (Hjermann et al. 2004), which subsequently recovered. Unlike capelin, tunas are not considered 'forage' species; however, the interaction strengths among tunas and their predators need not be symmetric for strong top-down interactions. For example, sharks and billfishes might still play a role in regulating these tunas even though they may not rely on tunas as an essential diet item. If these fishes do exert consumer control on skipjack and yellowfin tunas, a recovery of these large predators could potentially alter the productivity of highly valued tuna species.

The concept of mesopredator release has received much attention in recent years (e.g. Elmhagen \& Rushton 2007, Baum \& Worm 2009, Prugh et al. 2009, Ritchie \& Johnson 2009, Brashares et al. 2010). While most studies of this ecological phenomenon are based in terrestrial and coastal marine ecosystems, there is accumulating evidence of this process in oceanic ecosystems. For instance, both short-term (Polovina et al. 2009) and long-term (Ward \& Myers 2005) changes in longline catch rates of mid- and high-trophic level pelagic fishes support the possibility of mesopredator release. Also, Worm \& Tittensor (2011) suggested that increases in the number and range of skipjack tuna in the eastern tropical Pacific Ocean could be attributed to the depletion of largebodied tunas, sharks and marlins. By identifying predator species that are most capable of exerting top-down control and the vulnerability of tunas by size to predation, our analyses provide a strong foundation to better explore the extent by which largebodied apex predators, particularly sharks and marlins, might affect tuna populations.

Identifying whether shark and billfish species do indeed regulate tuna through predation processes is a challenging task. A strong top-down interaction is likely if a predator represents an important source of total mortality on tunas and if the predation mortality strongly depends on predator abundance (Essington \& Hansson 2004). An evaluation of whether these 2 criteria are met requires knowledge of predator feeding rates on tuna life stages as well as predator and prey relative abundances. This information is not available for many oceanic predators because of the sampling and data challenges associated with open ocean ecosystems (Baum \& Worm 2009). Consequently, attempts to identify consumer control within these systems have been limited. A food web model of the north Pacific subtropical gyre has been used to evaluate the trophic effects of predator removals on food web components in this region (Kitchell et al. 1999, 2002, Cox et al. 2002). Some model scenarios did not reveal evidence of mesopredator release in 
response to fisheries removals of apex predators (Kitchell et al. 2002), while others suggested that increased biomass of small tropical tunas, particularly yellowfin tuna, resulted from reduced predation by sharks and billfishes (Cox et al. 2002). Large food web models are often fit to fishery-dependent data and therefore are limited by the large uncertainties associated with the vagaries introduced by nonconstant catchability and spatial dynamics of fishing fleets (Walters 2003, Maunder et al. 2006).

The question of top-down control of tropical tunas remains to be answered. Future work is needed to evaluate how skipjack and yellowfin tunas may respond to changes in predator abundances and whether trophic interactions need to be accounted for more explicitly in the assessments of these tuna species. Our study provides a detailed analysis of predator-prey interactions and knowledge about potentially important predators on tunas and vulnerability by size to predation. We envision a potential next step as one that incorporates our findings in an age-structured population-modeling framework to assess the effects that sharks and billfishes have on stock productivity under various levels of predation mortality. Also, tropical tunas, especially yellowfin tuna, interact with these apex predators through competition for shared prey resources; therefore, mechanisms of competition need to be addressed when modeling the population dynamics of tunas under increased predation. An important consideration in future analyses will be the calculation of the range in common biological reference points that can be attributed to changes in predator stocks. This information can then be used to further evaluate whether diminished levels of large pelagic fishes have enhanced the production of tuna stocks. Alternatively, reductions in apex predators could lead to increased competition, or increased predation, or both, on tunas from other species.

The role of cannibalism in the population dynamics and persistence of tropical tunas, particularly skipjack tuna, also warrants further attention. Cannibalism is widespread in marine fish populations and can represent a major source of mortality on juvenile fishes (Smith \& Reay 1991). Cannibalism can serve as a density-dependent mechanism for population regulation (Anderson \& Gregory 2000, Neuenfeldt \& Köster 2000, Wespestad et al. 2000), while also providing a source of nutrition to adult fishes when alternative food sources are lacking. Through our analysis of summarized food habits data we found a notable occurrence of conspecifics in the diet of skipjack tuna. Our estimates of skipjack cannibalism are not as high as those for some marine fishes (e.g. gadoids; see Juanes 2003). However, skipjack tuna have high consumption and production rates and high biomass; they are the most abundant of the assessed predator stocks in the tropical Pacific Ocean. Thus, adult conspecifics could have a substantial effect on the recruitment of juvenile fishes and act as an important structuring force on the population, even if the juveniles comprised only a small component of the adult diet. Yellowfin tuna appeared to be minor predators on themselves. A low occurrence of yellowfin tuna cannibalism is not surprising because the adults are known to feed mainly near the thermocline, while the larval and juvenile stages occupy surface waters (see Longhurst 2010). The frequency and quantity of yellowfin tuna predation on skipjack tuna was considerable, although yellowfin tuna consumed only small-sized skipjack and conspecifics that have less reproductive potential because of cumulative mortality before spawning. If large-bodied tunas do have a predation effect on skipjack and yellowfin tunas it is likely to act primarily on pre-recruits and be manifested through recruitment (i.e. age at which tunas are first vulnerable to fishing gear).

An interesting outcome of our work is the evidence of a possible gradient of predation on skipjack tuna by large predators between the eastern and western tropical Pacific Ocean. This finding is supported by previous evidence that suggests that skipjack tuna is a major prey item of conspecifics and top predators in western and central regions of the tropical Pacific Ocean (Allain et al. 2007) and is less important as prey in the eastern region (Olson \& Watters 2003). This trend could arise because of regional differences in productivity and prey availability. For example, the eastern tropical Pacific Ocean has large upwelling regions (Fiedler \& Talley 2006) and thereby is highly productive and supports a large biomass and size spectrum of forage items, including epipelagic fishes and small scombrids (e.g. frigate tuna Auxis thazard and bullet tuna A. rochei) that are consumed by top predators. In comparison, the central and western regions are less productive, and thus we may expect that the availability and biomass of midtrophic level prey species is much lower in these areas. If this is true, then sharks, marlins and largebodied tunas are likely to depend more heavily on the large biomass of skipjack tuna for sustenance in the central and western tropical Pacific Ocean than in the eastern region, where there are many alternative prey items. The gradient of predation could also be attributed to the spatial distribution of skipjack tuna. For example, according to the catch of purse 
seine and pole-and-line fisheries, larger-sized skipjack tuna are more abundant in the central Pacific Ocean compared with the western Pacific Ocean (Hoyle et al. 2010). If the mean sizes of skipjack tuna do indeed increase eastward across the Pacific Ocean, then predation on these tunas may be more limited by constraints of body size in the eastern region compared with the central and western regions.

Our analysis revealed that predation on tunas by large pelagic fishes sampled from purse-seine floating-object sets (primarily FADs) was greater than for those captured via other methods. Specifically, capture method was an important predictor of both the frequency of occurrence and conditional percent mass contribution for both skipjack and yellowfin tunas. In all cases, the occurrence of predation was strongest from samples collected in floating-object sets, which suggests that floating objects potentially modify the pelagic habitat by aggregating small-sized skipjack, yellowfin, and bigeye tunas and thereby enhance their vulnerability to predators. It is plausible that capture method might also explain some of the discrepancies in predation intensity estimated from primary and summarized data. For example, the summarized data for sharks and marlins are mostly based on predators captured in local, artisanal fisheries and not by commercial fishing methods. However, differences in predator species composition and capture locations that comprise the primary and summarized data could contribute to the discrepancies as well. Previous authors (e.g. Dempster \& Taquet 2004) have voiced concern over the ecological consequences of deploying large numbers of FADs to target highly valued tunas. Our analysis supports a hypothesis that the use of floating-object sets in pelagic fisheries could be altering trophic interactions and feeding patterns in a way that increases predation pressure on small-bodied tunas.

Acknowledgements. We acknowledge all the authors who have collected and published data on the feeding habits of large pelagic predators in the tropical Pacific Ocean. We thank F. Galván-Magaña and E. Cortés for their thoughtful ideas and suggestions for improving this project. The manuscript benefited from a review by W. Bayliff. We thank the editor and 4 anonymous reviewers for their suggestions for improving the manuscript. This project was funded by Cooperative Agreement NA17RJ1230 between the Joint Institute for Marine and Atmospheric Research (JIMAR) and the National Oceanic and Atmospheric Administration (NOAA). The views expressed herein are those of the authors and do not necessarily reflect the views of NOAA or any of its subdivisions.

\section{LITERATURE CITED}

Akaike H (1973) Information theory and an extension of the maximum likelihood principle. In: Petrova BN, Csaki F (eds) Proceedings of the 2nd international symposium on information theory. Publishing House of the Hungarian Academy of Sciences, Budapest, p 268-281

Allain V, Nicol S, Essington TE, Okey TA, Olson RJ, Kirby DS (2007) An Ecopath with Ecosim model of the western and central Pacific Ocean warm pool pelagic ecosystem. In: 3rd meeting of the Scientific Committee of the Western and Central Pacific Fisheries Commission, WCPFCSC3. EB SWG/IP-8. Honolulu, HI, p 1-42

Alverson FG (1963) The food of yellowfin and skipjack tunas in the Eastern Tropical Pacific Ocean. Inter-Am Trop Tuna Comm Bull 7:293-367

Anderson JT, Gregory RA (2000) Factors regulating survival of northern cod (NAFO 2J3KL) during their first 3 years of life. ICES J Mar Sci 57:349-359

Baum JK, Worm B (2009) Cascading top-down effects of changing oceanic predator abundance. J Anim Ecol 78: 699-714

Baum JK, Myers RA, Kehler DG, Worm B, Harley SJ, Doherty PA (2003) Collapse and conservation of shark populations in the Northwest Atlantic. Science 299: 389-392

Bayliff WH (1988) Growth of skipjack, Katsuwonus pelamis, and yellowfin, Thunnus albacares, tunas in the eastern Pacific Ocean as estimated from tagging data. Inter-Am Trop Tuna Comm Bull 19:307-385

Brashares JS, Prugh LR, Stoner CJ, Epps CW (2010) Ecological and conservation implications of mesopredator release. In: Terborgh J, Sough M (eds) Trophic cascades: predators, prey, and the changing dynamics of nature. Island Press, Washington, DC, p 221-240

Brock RE (1984) A contribution to the trophic biology of the blue marlin (Makaira nigricans Lacépéde, 1802) in Hawaii. Pac Sci 38:141-149

Burnham KP, Anderson DR (2002) Model selection and multimodel inference: a practical information-theoretic approach. Springer, New York, NY

Caddy JF, Seijo JC (2002) Reproductive contributions foregone with harvesting: a conceptual framework. Fish Res 59:17-30

Cortes E (1999) Standardized diet compositions and trophic levels of sharks. ICES J Mar Sci 56:707-717

- Cox SP, Essington TE, Kitchell JF, Martell SJD, Walters CJ, Boggs C, Kaplan I (2002) Reconstructing ecosystem dynamics in the central Pacific Ocean, 1952-1998. II. A preliminary assessment of the trophic impacts of fishing and effects on tuna dynamics. Can J Fish Aquat Sci 59: 1736-1747

Daan N, Gislason H, Pope JG, Rice JC (2005) Changes in the North Sea fish community: Evidence of indirect effects of fishing? ICES J Mar Sci 62:177-188

> Daskalov GM, Grishin AN, Rodionov S, Mihneva V (2007) Trophic cascades triggered by overfishing reveal possible mechanisms of ecosystem regime shifts. Proc Natl Acad Sci USA 104:10518-10523

> Dempster T, Taquet M (2004) Fish aggregation device (FAD) research: gaps in current knowledge and future directions for ecological studies. Rev Fish Biol Fish 14:21-42

> Elmhagen B, Rushton SP (2007) Trophic control of mesopredators in terrestrial ecosystems: Top-down or bottomup? Ecol Lett 10:197-206 
Essington TE (2010) Ecological indicators display reduced variation in North American catch share fisheries. Proc Natl Acad Sci USA 107:754-759

Essington TE, Hansson S (2004) Predator-dependent functional response and interaction strengths in a natural food web. Can J Fish Aquat Sci 61:2215-2226

Estes JA, Tinker MT, Williams TM, Doak DF (1998) Killer whale predation on sea otters linking oceanic and nearshore ecosystems. Science 282:473-476

Fiedler PC, Talley LD (2006) Hydrography of the eastern tropical Pacific: a review. Prog Oceanogr 69:143-180

Frank KT, Petrie B, Choi JS, Leggett WC (2005) Trophic cascades in a formerly cod-dominated ecosystem. Science 308:1621-1623

> Gallucci VF, Taylor IG, Erzini K (2006) Conservation and management of exploited shark populations based on reproductive value. Can J Fish Aquat Sci 63:931-942

Gelman A, Hill J (2007) Data analysis using regression and multilevel / hierarchical models. Cambridge University Press, Cambridge

Gotelli NJ (2001) A primer of ecology. Sinauer Associates, Sunderland, MA

> Hampton J (2000) Natural mortality rates in tropical tunas: size really does matter. Can J Fish Aquat Sci 57: $1002-1010$

Hjermann DØ, Ottersen G, Stenseth NC (2004) Competition among fishermen and fish causes the collapse of Barents Sea capelin. Proc Natl Acad Sci USA 101:11679-11684

Hoyle S, Kleiber P, Davies N, Harley S, Hampton J (2010) Stock assessment of skipjack tuna in the Western and Central Pacific Ocean. 6th Meeting of the Scientific Committee of the Western and Central Pacific Fisheries Commission, 10-19 August 2010. WCPFC-SC6-2010/ SA-WP-10, Nuku'alofa, Tonga

> Jackson JBC, Kirby MX, Berger WH, Bjorndal KA and others (2001) Historical overfishing and the recent collapse of coastal ecosystems. Science 293:629-637

> Jensen OP, Seppelt R, Miller TJ, Bauer LJ (2005) Winter distribution of blue crab (Callinectes sapidus) in Chesapeake Bay: application and cross-validation of a twostage generalized additive model (GAM). Mar Ecol Prog Ser 299:239-255

> Juanes F (2003) The allometry of cannibalism in piscivorous fishes. Can J Fish Aquat Sci 60:594-602

Kaplan IC, Cox SP, Kitchell JF (2007) Circle hooks for Pacific longliners: not a panacea for marlin and shark bycatch, but part of the solution. Trans Am Fish Soc 136:392-401

Kerstetter DW, Graves JE (2006) Effects of circle versus Jstyle hooks on target and non-target species in a pelagic longline fishery. Fish Res 80:239-250

King JE, Ikehara II (1956) Comparative study of food of bigeye and yellowfin tuna in the central Pacific. Fish Bull 57: 61-85

Kitchell JF, Boggs C, He X, Walters CJ (1999) Keystone predators in the Central Pacific. In: Ecosystem approaches to fisheries management. University of Alaska Sea Grant, AL-SG-99-01, Fairbanks, AK, p 665-683

> Kitchell JF, Essington TE, Boggs CH, Schindler DE, Walters CJ (2002) The role of sharks and longline fisheries in a pelagic ecosystem of the central Pacific. Ecosystems 5: 202-216

Kitchell JF, Kaplan IC, Cox SP, Martell SJD, Essington TE, Boggs CH, Walters CJ (2004) Ecological and economic components of alternative fishing methods to reduce bycatch of marlin in a tropical pelagic ecosystem. Bull Mar
Sci 74:607-619

Longhurst A (2010) Mismanagement of marine fisheries. Cambridge University Press, Cambridge

Maunder MN (2007) Status of skipjack tuna in the eastern Pacific Ocean in 2006 and outlook. Inter-Am Trop Tuna Comm Stock Assess Rep 8. Inter-American Tropical Tuna Commission, La Jolla, CA

Maunder MN, Aires-da-Silva A (2009) Status of yellowfin tuna in the eastern Pacific Ocean in 2007 and outlook for the future. Inter-Am Trop Tuna Comm Stock Assess Rep 9. Inter-American Tropical Tuna Commission, La Jolla, CA

Maunder MN, Harley SJ (2005) Status of skipjack tuna in the eastern Pacific Ocean in 2003 and outlook for 2004. Inter-Am Trop Tuna Comm Stock Assess Rep 5. InterAmerican Tropical Tuna Commission, La Jolla, CA

> Maunder MN, Punt AE (2004) Standardizing catch and effort data: a review of recent approaches. Fish Res 70: 141-159

$>$ Maunder MN, Sibert JR, Fonteneau A, Hampton J, Kleiber P, Harley S (2006) Interpreting catch-per-unit-of-effort data to assess the status of individual stocks and communities. ICES J Mar Sci 63:1373-1385

> Minami M, Lennert-Cody C, Gao W, Román-Verdesoto M (2007) Modeling shark bycatch: the zero-inflated negative binomial regression model with smoothing. Fish Res 84:210-221

> Neuenfeldt S, Köster FW (2000) Trophodynamic control on recruitment success in Baltic cod: the influence of cannibalism. ICES J Mar Sci 57:300-309

Olson R, Watters G (2003) A model of the pelagic ecosystem in the eastern tropical Pacific Ocean. Inter-Am Trop Tuna Comm Bull 22:135-218

> Pauly D (1995) Anecdotes and the shifting baseline syndrome in fisheries. Trends Ecol Evol 10:430

Pine WE III, Martell SJD, Jensen OP, Walters CJ, Kitchell JF (2008) Catch-and-release and size limit regulations for blue, white, and striped marlin: the role of post release survival in effective policy design. Can J Fish Aquat Sci 65:975-988

Pinnegar JK, Engelhard GH (2008) The 'shifting baseline' phenomenon: a global perspective. Rev Fish Biol Fish 18: $1-16$

Polovina JJ, Abecassis M, Howell EA, Woodworth P (2009) Changes among trophic levels in the central North Pacific subtropical gyre ecosystem, 1996-2000. Fish Bull 107:523-531

> Prugh LR, Stoner CJ, Epps CW, Bean WT, Ripple WJ, Laliberte AS, Brashares JS (2009) The rise of the mesopredator. Bioscience 59:779-791

R Development Core Team (2010) R: A language and environment for statistical computing. R Foundation for Statistical Computing, Vienna

Reum JCP, Essington TE, Greene CM, Rice CA, Fresh KL (2011) Multiscale influence of climate on estuarine populations of forage fish: the role of coastal upwelling, freshwater flow and temperature. Mar Ecol Prog Ser 425: 203-215

Ritchie EG, Johnson CN (2009) Predator interactions, mesopredator release and biodiversity conservation. Ecol Lett 12:982-998

Román-Verdesoto M, Orozco-Zöller M (2005) Bycatches of sharks in the tuna purse-seine fishery of the eastern Pacific Ocean reported by observers of the InterAmerican Tropical Tuna Commission,1993-2004. Inter- 
Am Trop Tuna Comm Data Rep 11. Inter-American Tropical Tuna Commission, La Jolla, CA

Schaefer KM (1998) Reproductive biology of yellowfin tuna (Thunnus albacares) in the eastern Pacific Ocean. InterAm Trop Tuna Comm Bull 21:205-272

Seki MP, Polovina JJ (2001) Ocean gyre ecosystems. In: Steele JH, Thorpe SA, Turekian KK (eds) The encyclopedia of ocean sciences, Vol 4. Academic Press, San Diego, CA, p 1959-1964

Sibert J, Hampton J, Kleiber P, Maunder M (2006) Biomass, size, and trophic status of top predators in the Pacific Ocean. Science 314:1773-1776

Smith C, Reay P (1991) Cannibalism in teleost fish. Rev Fish Biol Fish 1:41-64

Stéquert B, Ramcharrun B (1995) Fecundity of skipjack tuna (Katsuwonus pelamis) from the Western Indian Ocean. Aquat Living Resour 8:79-89

Wallace BP, Heppell SS, Lewison RL, Kelez S, Crowder LB (2008) Impacts of fisheries bycatch on loggerhead turtles worldwide inferred from reproductive value analyses. J Appl Ecol 45:1076-1085

- Wallace BP, Lewison RL, McDonald SL, McDonald RK and others (2010) Global patterns of marine turtle bycatch. Conserv Lett 3:131-142

- Walters C (2003) Folly and fantasy in the analysis of spatial catch rate data. Can J Fish Aquat Sci 60:1433-1436

Editorial responsibility: Hans-Heinrich Janssen, Oldendorf/Luhe, Germany
Ward P, Myers RA (2005) Shifts in open-ocean fish communities coinciding with the commencement of commercial fishing. Ecology 86:835-847

Watson JT, Essington TE, Lennert-Cody CE, Hall MA (2009) Trade-offs in the design of fishery closures: management of silky shark bycatch in the eastern Pacific Ocean tuna fishery. Conserv Biol 23:626-635

> Wespestad VG, Fritze LW, Ingraham WJ, Megrey BA (2000) On relationships between cannibalism, climate variability, physical transport, and recruitment success of Bering Sea walleye pollock (Theragra chalcogramma). ICES J Mar Sci 57:272-278

Wild A (1986) Growth of yellowfin tuna, Thunnus albacares, in the eastern tropical Pacific Ocean based on otolith increments. Inter-Am Trop Tuna Comm Bull 18:421-482

Williams TM, Estes JA, Doak DF, Springer AM (2004) Killer appetites: assessing the role of predators in ecological communities. Ecology 85:3373-3384

Worm B, Myers RA (2003) Meta-analysis of cod-shrimp interactions reveals top-down control in oceanic food webs. Ecology 84:162-173

Worm B, Tittensor DP (2011) Range contraction in large pelagic predators. Proc Natl Acad Sci USA 108: 11942-11947

Zar JH (1999) Biostatistical analysis. Prentice Hall, Englewood Cliffs, NJ

Submitted: April 20, 2011; Accepted: November 11, 2011

Proofs received from author(s): January 8, 2012 